\section{Nail Patella Syndrome}

A 12-yr-old girl presented with the chief complaints of mild bilateral knee pain more on the right side for six months duration. The pain was gradual in onset and slowly progressive. The pain was felt particularly while walking a distance of more than a kilometer and while running or playing. She also denied any history of recent or old trauma to the knees. On examination, nail dysplasia was present involving thumb and index fingers bilaterally. Knee examination revealed laterally placed hypoplastic patellae bilaterally. No other abnormality was detected clinically. Radiograph of both knees confirmed the clinical findings of hypoplastic and laterally placed patella bilaterally (Fig. 1a, b). Radiograph of pelvis (AP view) showed presence of iliac horns on both sides (Fig. 2). Radiograph of both elbows was normal. Ultrasonography of the abdomen with special reference to the kidneys was found to be normal. Her routine hematological and biochemical parameters were also within normal limit. Based on the clinical and radiographic findings, diagnosis of NPS was made.

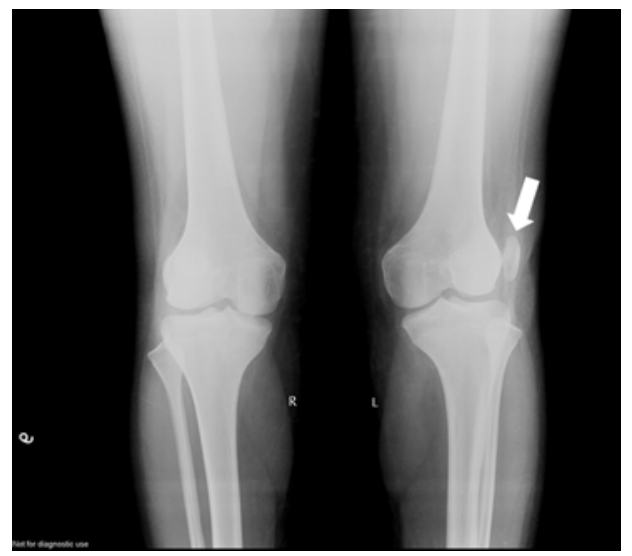

Fig. 1a

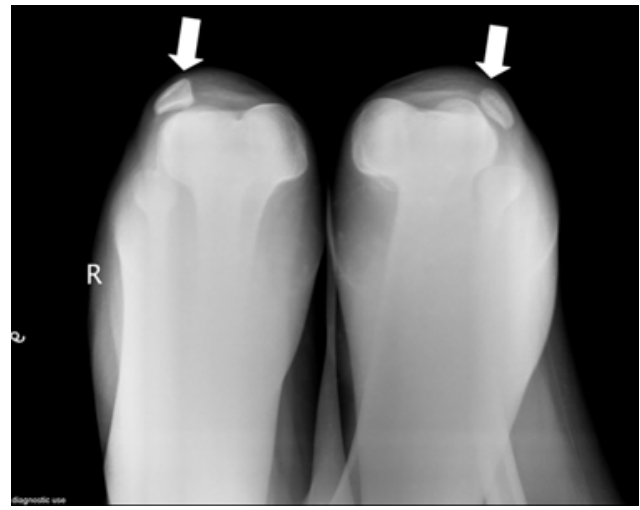

Fig. 1b

Fig. 1a, b. Radiograph of both knees showing hypoplastic and laterally placed patella bilaterally (arrows)

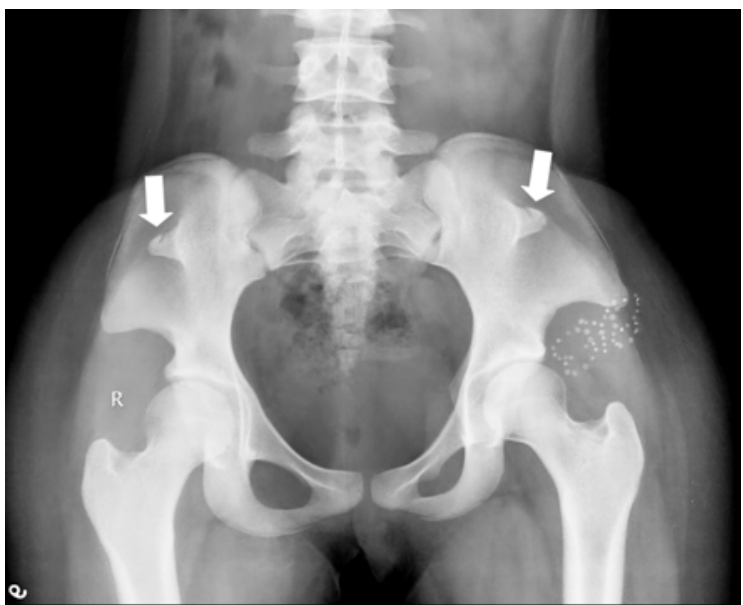

Fig. 2. Radiograph of pelvis (AP view) showing presence of iliac horns on both sides (arrows).

Nail patella syndrome (NPS) also known as osteoonychodysplasia or Fong's syndrome is a rare hereditary disorder with an incidence of about 4.5 per million in the United States. ${ }^{1}$ The disease is transmitted as autosomal dominant trait with variable expression and the underlying genetic defect has been localized to LMX1B gene on chromosome $9 .^{2}$ Besides the characteristic involvement of patellae, radial head and presence of posterior iliac horns, various other abnormalities described with NPS include antecubital pterygium, clavicular horn, shoulder girdle dysplasia, congenital absence of fibula, bilateral first rib

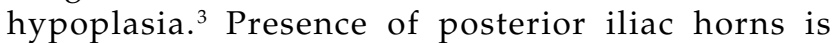
considered pathognomonic of NPS and has been observed in more than 80 per cent of cases. It is also possible to diagnose this condition on prenatal ultrasonography. ${ }^{4}$

Chandan Jyoti Das and Jyotindu Debnath Department of Radiodiagnosis All India Institute of Medical Sciences, Ansari Nagar, New Delhi-110029, India E-mail:dascj@yahoo.com

\section{REFERENCES}

1. Goshen E, Schwartz A, Zilka LR, Zwas ST. Bilateral accessory iliac horns: pathognomonic findings in Nailpatella syndrome. Scintigraphic evidence on bone scan. Clin Nucl Med 2000; 25: 476-477.

2. Dreyer SD, Zhou G, Baldini A et al. Mutations in LMX1B cause abnormal skeletal patterning and renal dysplasia in nail-patella syndrome. Nat Genet 1998; 19: 47-50.

3. Juma AH. Nail-patella syndrome in Saudi Arabia with new features and surgical procedures: the first described study. Med Gen Med 2004; 6: 6.

4. Pinette MG, Ukleja M, Blackstone J. Early prenatal diagnosis of nail-patella syndrome by ultrasonography. J Ultrasound Med 1999; 18: 387-389. 